\title{
Speckle Cross-Correlation Method in Measuring Fine Surface Displacements
}

\author{
M. Bahrawi, N. Farid, and M. Abdel-Hady \\ Optical Metrology Department, National Institute for Standards, Tersa Street, Haram, P.O. Box 136, Giza 12211, Egypt \\ Correspondence should be addressed to N. Farid, niveen_farid@hotmail.com
}

Received 7 July 2012; Revised 27 October 2012; Accepted 27 October 2012

Academic Editor: Keli Han

Copyright $\odot 2012$ M. Bahrawi et al. This is an open access article distributed under the Creative Commons Attribution License, which permits unrestricted use, distribution, and reproduction in any medium, provided the original work is properly cited.

Industrial applications need regular testing for the lifetime, movement, strength, and performance of manufacturing machines during production process. Since speckle photography is a simple economic technique, it is used in investigating object response under mechanical and thermal effects depending on the movement of the speckle patterns with respect to the deformation strength and direction. In the present work, the cross-correlation technique is used to analyze the speckle patterns by iterative method to define both values and directions of rigid body translation and expansion. In order to check the accuracy of the cross-correlation technique, the results are compared with the displacement values given by analyzing the Young's interference fringes resulted from the Fourier transformation of the speckle patterns. This noncontact technique is found to be accurate and informative depending on the stability and sensitivity of the optical system. This method of measurement is an effective tool in studying the hard cases of objects and machines under various effects.

\section{Introduction}

The necessity to ensure the efficiency of machines and tools used in industrial applications requires regular testing of their ability to work under various effects such as vibration and temperature. The conventional methods of investigation require surface contact and could be limited to object materials and time of measurements. In order to maintain the quality of the object and to make the testing service possible any time and under any circumstances, it is important to use a simple nondestructive method in the investigation.

Electronic speckle photography is a simple nondestructive technique used in investing object variation under different effects. The investigation using this technique is performed by analyzing several recorded images for the object surface before and after deformation. The variation of speckle patterns position and interference fringes' visibility indicate the direction and the strength of the deformation that the object encountered. Previous work discussed methods for characterizing object displacement and surface roughness by analyzing Young's interference fringes resulted by the Fourier transformation of the combined speckle images before and after deformation [1, 2]. This method is reliable in indicating value of displacement but not field of displacement. The cross-correlation method describes the displacement field by the maximum position of the crosscorrelation function between the speckle patterns recorded before and after displacement or deformation. The processed data lead to estimating and visualizing the displacement field with accuracy depending on the resolution of the recording sensor and the stability of the optical system. The simplicity of the experimental setup and the accuracy of the processing method increase the applications of this technique in surface engineering science by studying the variation of the speckle patterns in sequence of images. The iterative method in the processing makes it possible to track surface deformation in a specific time.

\section{Measuring System}

The system setup is very simple since it consists of a $\mathrm{He}-\mathrm{Ne}$ laser and a high resolution recording sensor as in Figure 1. The object of interest is a rectangular piece of aluminum of dimensions $(35 \times 30 \times 8) \mathrm{mm}$. 


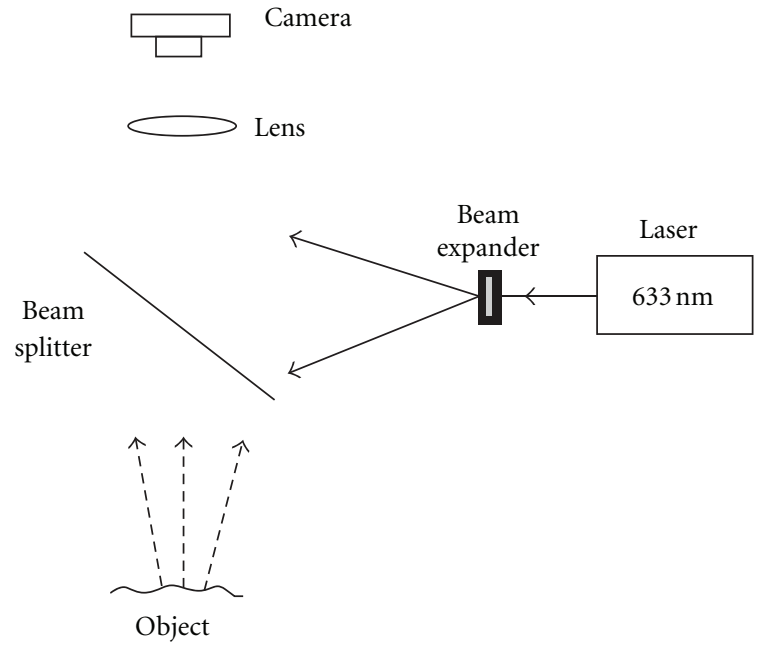

(a)
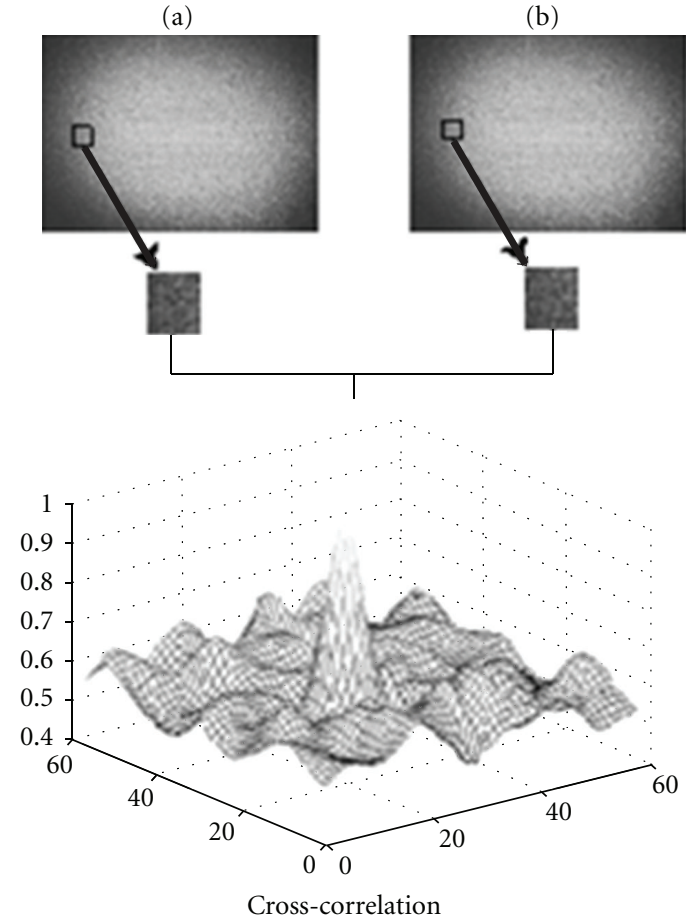

FIGURE 1: Measuring system for identifying surface displacement.

The light beams are expanded and directed to the object's surface, and the scattered beams are then collected by a converging lens and directed to the sensor. Sequence of images is taken for the object when it is shifted laterally and also when its temperature is raised. The first image is considered as the zero case and other images represent the gradual variation from the reference one. The recorded images are divided into subimages, and the speckle movement is tracked in order to extract the surface displacement vectors defined by length and direction and determined by the maximum correlation. Larger subimage size which contains more speckle patterns is more informative and more accurate. Although the system is easy to set up, it provides complete data analysis for different kinds of materials and deformations.

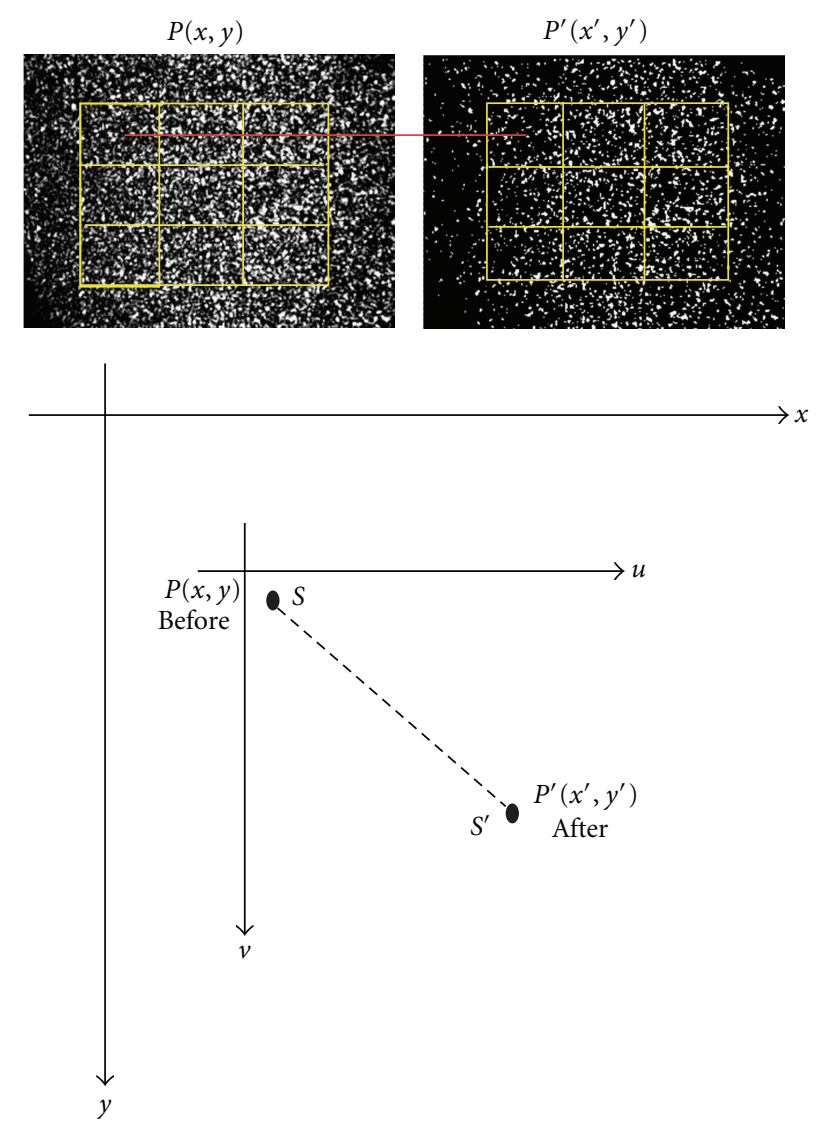

Figure 2: Object images shifted by the displacement fields $u(x, y)$ and $v(x, y)$.

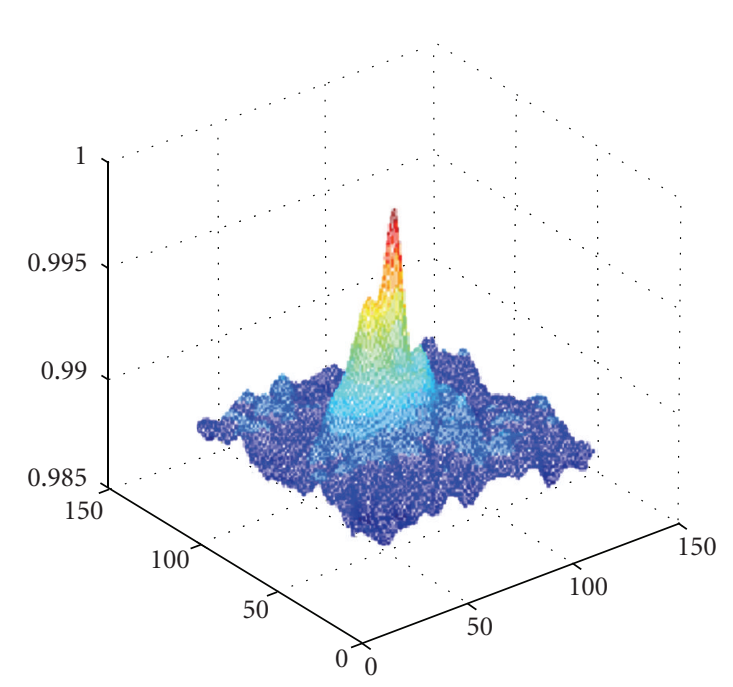

Figure 3: Cross-correlation function.

\section{Theoretical Aspects}

The cross-correlation technique or image matching technique matches the speckle patterns in the selected area of interest of object's images (Figure 2). The sequential images are compared to estimate the relative motion of the object's 

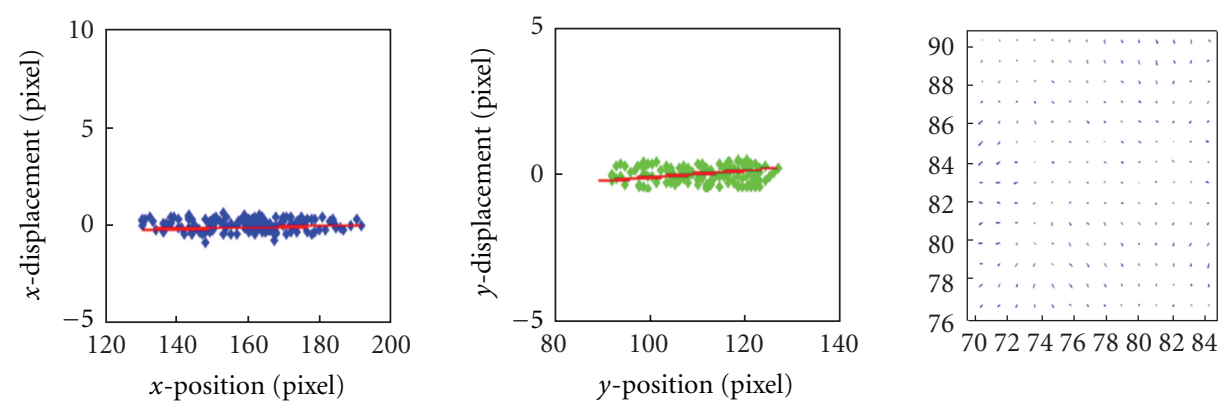

(a) Stability of the optical system
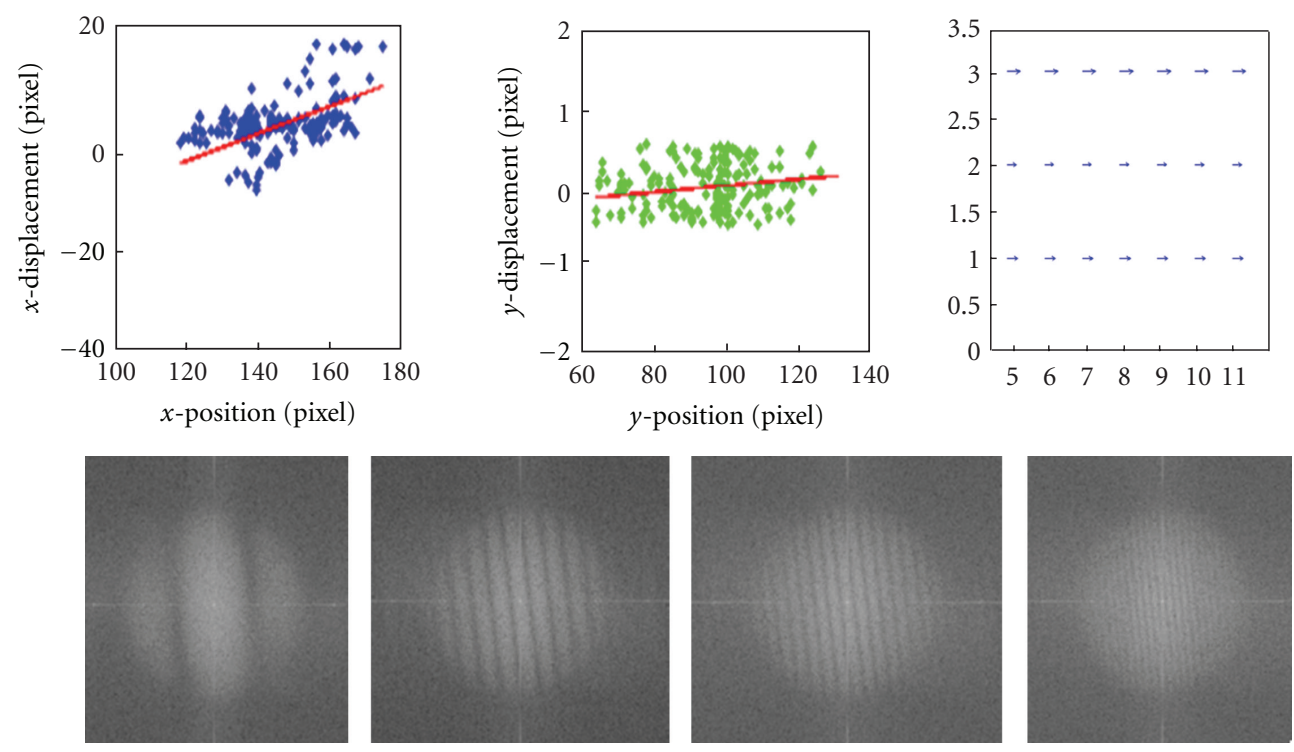

(b) Displacement due to lateral mechanical shifting
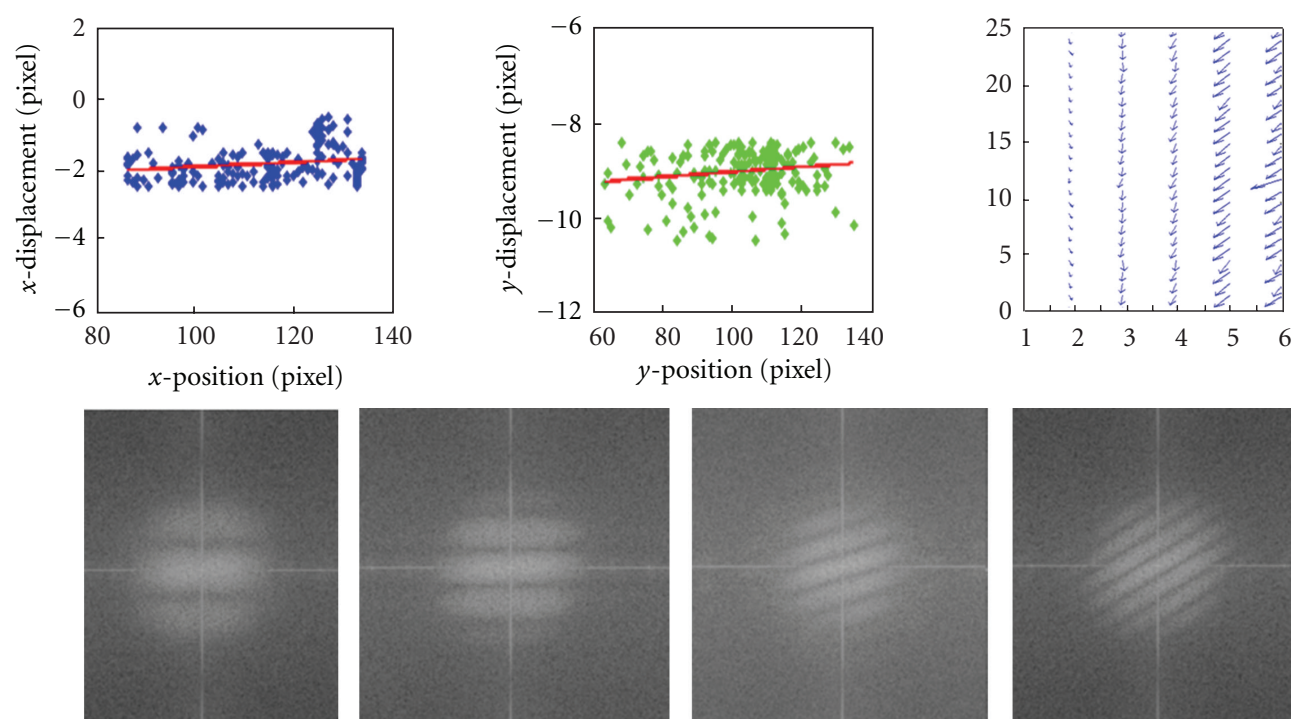

(c) Displacement due to rigid displacement and heating

Figure 4: Displacement of object's surface versus $x$ - and $y$-positions. 


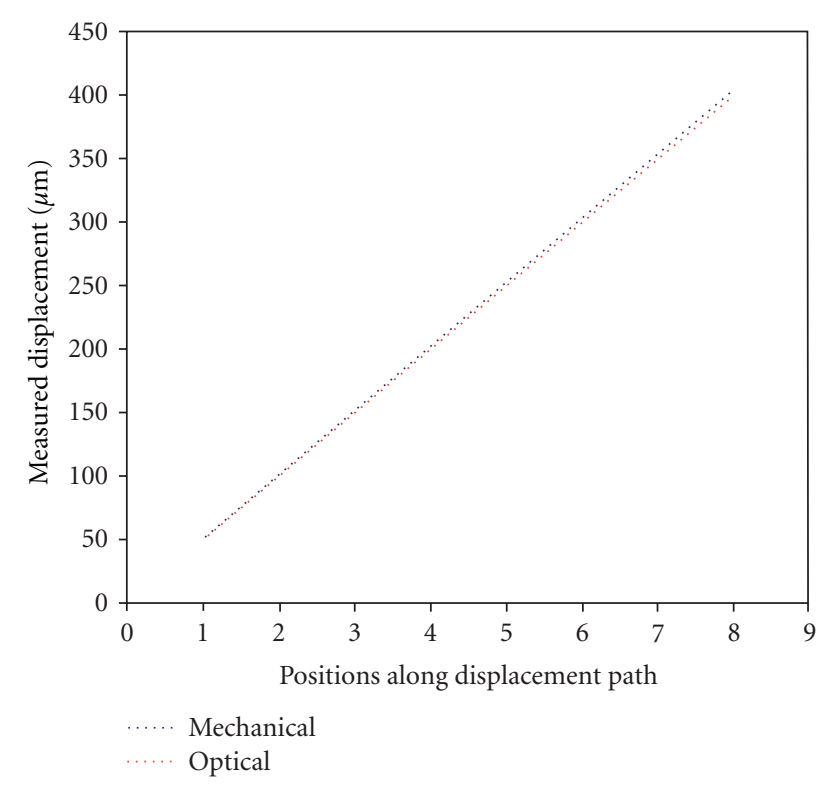

FIGURE 5: Optical measurements versus mechanical readings of lateral displacements.

surface imaged during displacement or heating. The variations occurred to the speckle patterns in an image with respect to other images are estimated by the correlation function. Assuming $p(x, y)$ is the reference image, and $p^{\prime}\left(x^{\prime}, y^{\prime}\right)$ is the displaced image, then the relation between the two functions is represented by the squared Euclidean distance $[3,4]$ :

$$
\Delta^{2}=\sum_{x, y}\left(P(x, y)-P^{\prime}(x-u(x, y), y-v(x, y))\right)^{2},
$$

where $u(x, y)$ and $v(v, y)$ are the displacement fields, and the expansion of this equation yields the cross-correlation function which finds the similarity between $p(x, y)$ and $p^{\prime}\left(x^{\prime}, y^{\prime}\right)$ $[5,6]$ :

$$
\begin{gathered}
C_{p p^{\prime}}=P(x, y)^{*} P^{\prime}(x-u(x, y), y-v(x, y)), \\
P^{*} P^{\prime}=\operatorname{FFT}^{-1}\left(\operatorname{FFT}\left(P^{*}\right) \operatorname{FFT}\left(P^{\prime}\right)\right) .
\end{gathered}
$$

For measuring the displacement fields $u(x, y)$ and $v(x, y)$, the normalized cross-correlation of the speckle patterns before and after surface displacement has to be evaluated, then the displacement from the maximum of the resultant crosscorrelation function is estimated as follows:

$$
\text { displacement field }=\text { object translation }+ \text { object strain. }
$$

Image grid defines the zones of interest from the initial to the final image, and the calculation is performed by the iterative process [7-11], then the displacement field following $x$ and $y$ axis is represented.

\section{Experimental Work and Discussion}

First sequence of images is taken for the object in the absence of any influence factors to check the stability of the optical system with respect to thermal effects and vibration. New sequence of images is taken while object is displaced laterally by precise travelling stage and other set sequence is taken during raising the object's temperature. The cross-correlation is evaluated for each sequence according to (3) to determine the field of displacement which is calculated at the maximum correlation using the quadratic interpolation (Figure 3). Initially, the displacement field is represented by small dots and indicates approximate zero surface displacement (Figure 4(a)). When the object is displaced laterally by the travelling stage, Young's interference fringes show variation in number and spacing as object moves, and formula (5) defines the displacement as a function of fringe spacing and wavelength [12]:

$$
\Delta l=\frac{\lambda R}{\Delta f}
$$

where $\Delta l$ is the displacement, $\lambda$ is the source wavelength, $\Delta f$ is the fringe spacing, and $R$ is the object separation from the detector. Image scale factor is calculated knowing the actual dimension at image plane and the number of pixels represented by this dimension, and the scale factor is found to be $0.2246(\mathrm{pixel} / \mathrm{mm})$.

Optical displacement determined by the interference fringes using (5) is $95 \mu \mathrm{m} \pm 5 \mu \mathrm{m}$. Using the cross-correlation technique to determine the displacement fields, the translation is found to be $90 \mu \mathrm{m} \pm 1 \mu \mathrm{m}$ in the $x$-axis and $1.5 \mu \mathrm{m} \pm$ $1 \mu \mathrm{m}$ in the $y$-axis (Figure $4(\mathrm{~b})$ ).

In order to test the out-of-plane effects during lateral shifting, the object is moved laterally using accurate translation stage, and the displacements detected by the interference fringes using (5) are compared to the mechanical system shifting values with resolution $0.1 \mu \mathrm{m}$. Both readings show good agreement and a small deviation is observed at the largest shift (Figure 5). This deviation indicates small parallelism error in the alignment of object and camera (out-ofplane effect). For this reason, the experimental work is made within a smaller range to avoid the deviation from in-plane displacement along the path.

In another case, the object is heated during displacement, so that the speckle cross-correlation identifies the displacement specified by translation as $10 \mu \mathrm{m} \pm 1 \mu \mathrm{m}$ in $x$ axis and $45 \mu \mathrm{m} \pm 1 \mu \mathrm{m}$ in $y$-axis, and the displacement is specified by the expansion as $4 \mu \mathrm{m} \pm 1 \mu \mathrm{m}$ in the $x$-axis and $4.45 \mu \mathrm{m} \pm 1 \mu \mathrm{m}$ in the $y$-axis (Figure $4(\mathrm{c})$ ). The measuring technique determines the displacement by tracking large number of image points with precision $( \pm 1 \mu \mathrm{m})$. Surface displacement over large number of points along $x-y$ axes is represented in Figure 6. The uncertainty in measurement is assessed according to [13] depending on the following factors:

(1) standard deviation of the results ( 0.1 pixel) divided by the scale factor, 


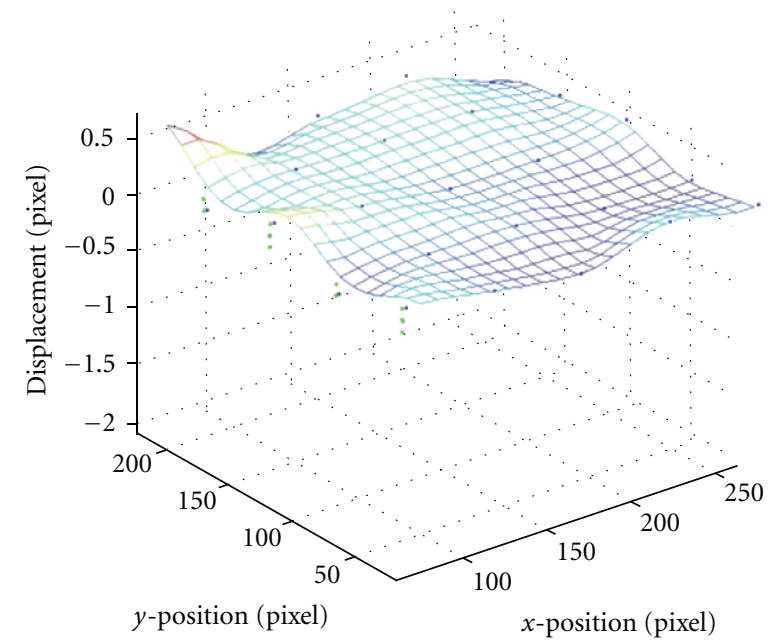

(a)

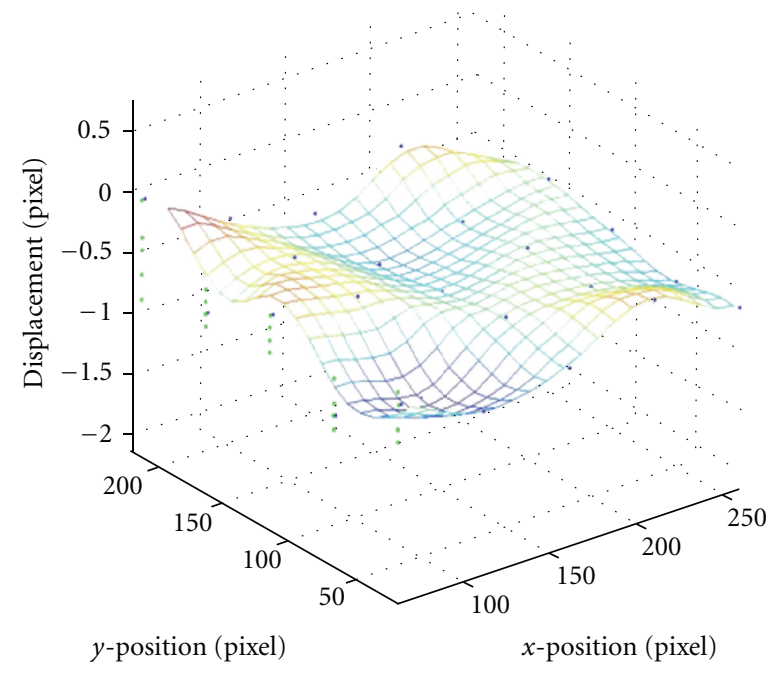

(c)

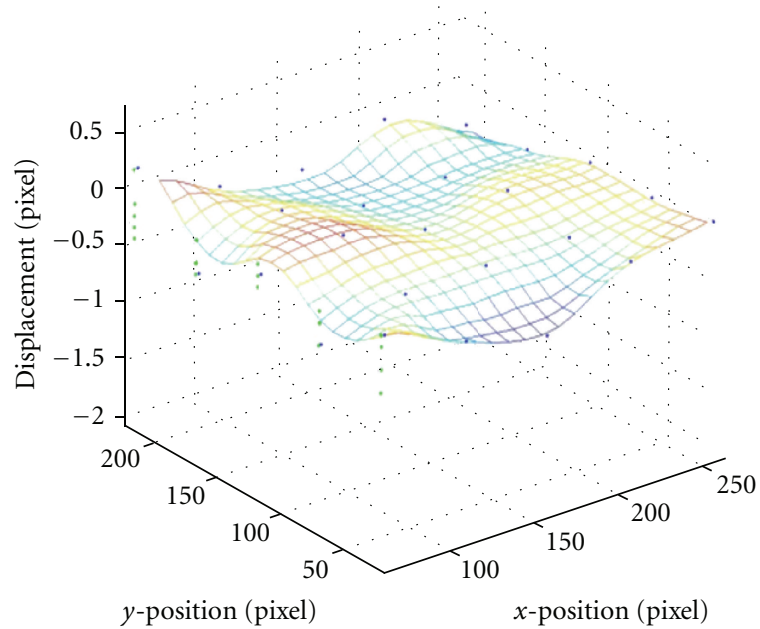

(b)

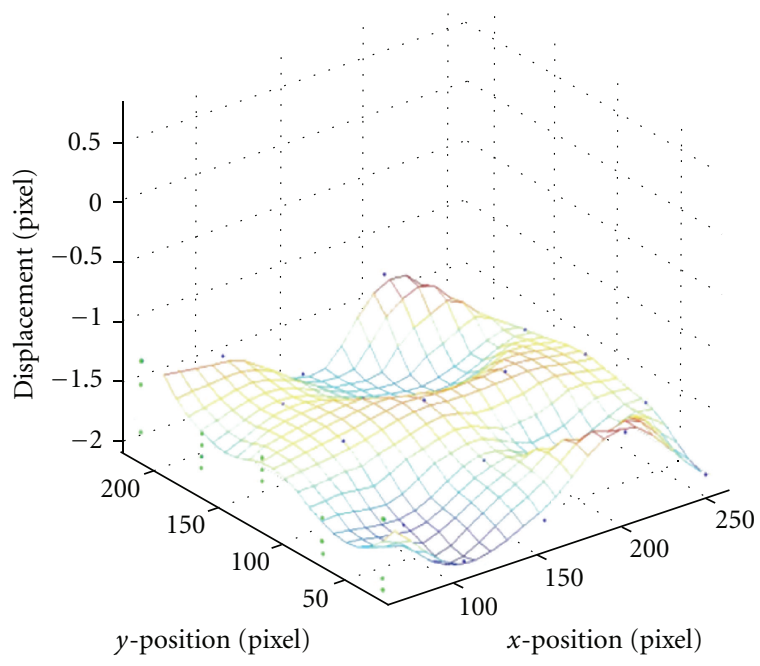

(d)

FIGURE 6: Surface points displacements including rigid translation and strain.

(2) resolution of the thermocouple $0.1{ }^{\circ} \mathrm{C}$ (that detects object temperature during experiment),

(3) stability of optical system,

(4) stability of laser wavelength (calibration certificate),

(5) effect of environmental factors (air refractive index).

\section{Conclusion}

Although the discussed technique is simple, it provides precise calculations of the displacement field for both rigid body translation and expansion through cross-correlation method. It is essential to adjust the contrast and the light uniformity in the recorded images. The stability of the optical system is studied as a first step. Sequence of images is then recorded under the effect of lateral shifting and thermal effect and the displacement field is determined with $\pm 1 \mu \mathrm{m}$ accuracy. The technique is compared to the conventional method of displacement measurement using Young's interference fringes analysis, and the comparison shows good agreement. This technique is capable to determine the displacement field in hard cases at short time with good precision.

\section{References}

[1] M. Nicklawy, A. F. Hassan, M. Bahrawi, N. Farid, and A. M. Sanjid, "Characterizing surface roughness by speckle pattern analysis," Journal of Scientific and Industrial Research, vol. 68, no. 2, pp. 118-121, 2009.

[2] M. Sjödahl, "Accuracy in electronic speckle photography," Applied Optics, vol. 36, no. 13, pp. 2875-2885, 1997.

[3] R. Duda and P. E. Hart, Pattern Classification and Scene Analysis, Wiley, New York, NY, USA, 1973.

[4] R. Gonzalez and R. E. Woods, Digital Image Processing, Addison-Wesley, Reading, Mass, USA, 1992.

[5] J. N. Périé, S. Calloch, C. Cluzel, and F. Hild, "Analysis of a multiaxial test on a $\mathrm{C} / \mathrm{C}$ composite by using digital image correlation and a damage model," Experimental Mechanics, vol. 42, no. 3, pp. 318-328, 2002. 
[6] T. C. Chu, W. F. Ranson, and M. A. Sutton, "Applications of digital-image-correlation techniques to experimental mechanics," Experimental Mechanics, vol. 25, no. 3, pp. 232244, 1985.

[7] M. Sutton, W. Wolters, W. Peters, W. Ranson, and S. McNeill, "Determination of displacements using an improved digital correlation method," Image and Vision Computing, vol. 1, no. 3, pp. 133-139, 1983.

[8] M. Sutton, C. Mingqi, W. Peters, Y. Chao, and S. McNeill, "Application of an optimized digital correlation method to planar deformation analysis," Image and Vision Computing, vol. 4, no. 3, pp. 143-150, 1986.

[9] M. A. Sutton, J. J. Orteu, and H. Schreier, Image Correlation For Shape, Motion and DeFormation Measurements-Basic Concepts, Theory and Applications, Springer, New York, NY, USA, 2009.

[10] M. A. Sutton, J. H. Yan, V. Tiwari, H. W. Schreier, and J. J. Orteu, "The effect of out-of-plane motion on 2D and 3D digital image correlation measurements," Optics and Lasers in Engineering, vol. 46, no. 10, pp. 746-757, 2008.

[11] I. Yamaguchi, "Measurement and testing by digital speckle correlation," in Proceeding of the 7th International Symposium on Instrumentation and Control Technology: Optoelectronic Technology and Instruments, Control Theory and Automation, and Space Exploration, vol. 7129 of Proceedings of SPIE, 2008.

[12] N. Farid, Application of speckle metrology as a tool for optical dimensional measurements [Ph.D. thesis], Helwan University, 2008.

[13] JCGM 100:2008, Evaluation of measurement data, Guide to the expression of uncertainty in measurement, 2008, http:// www.bipm.org/utils/common/documents/jcgm/JCGM_100_ 2008_E.pdf. 

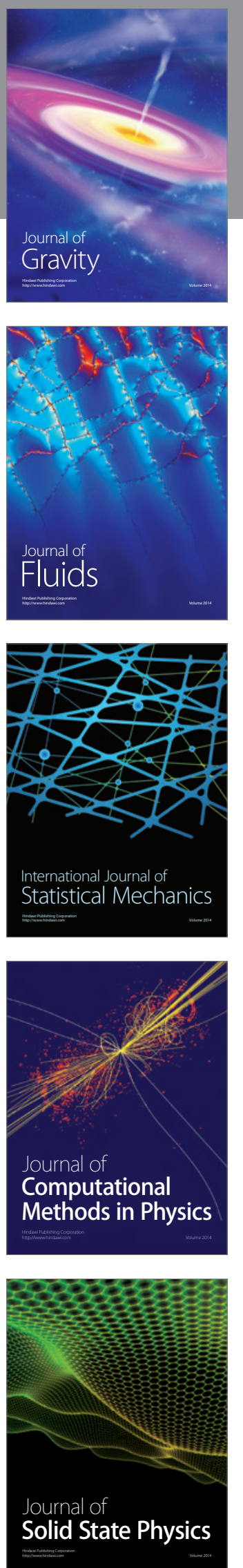

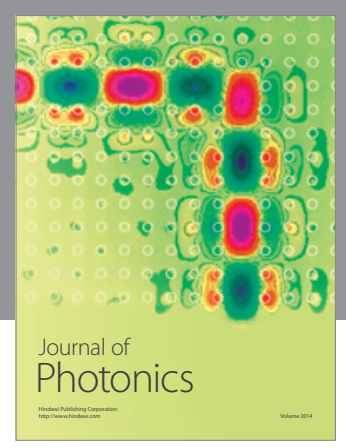

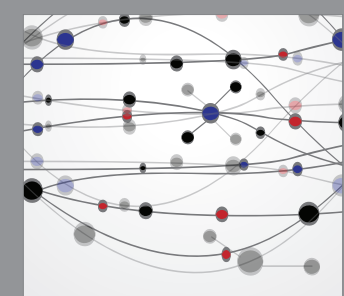

The Scientific World Journal
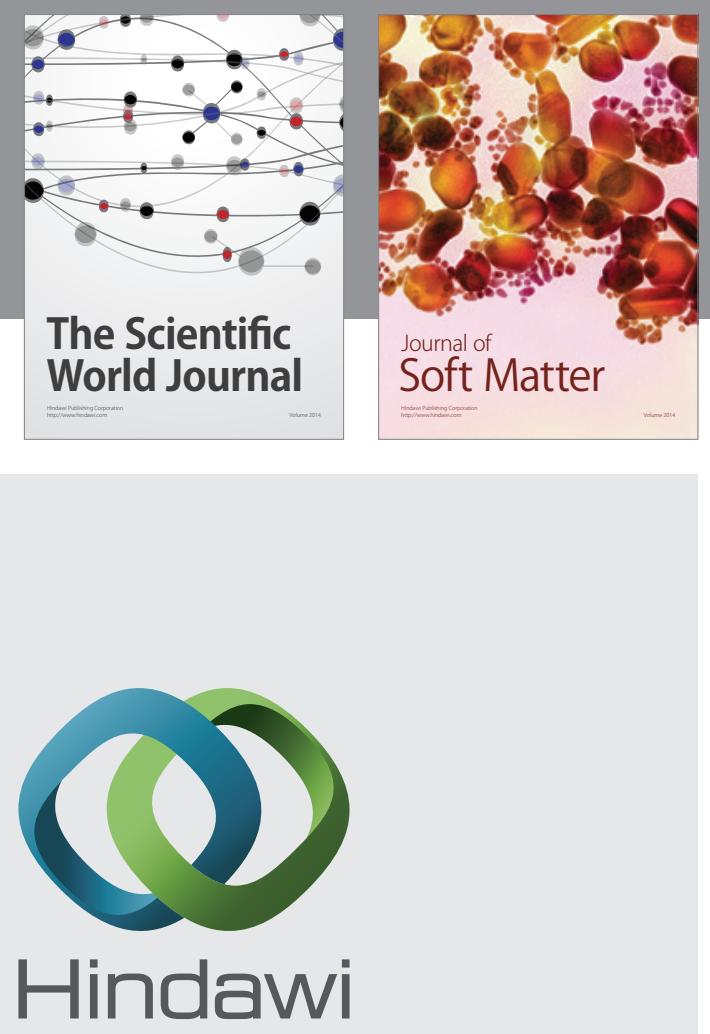

Submit your manuscripts at

http://www.hindawi.com
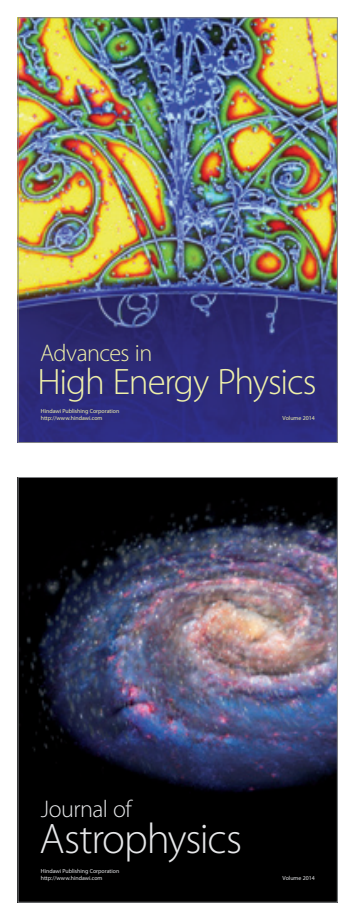
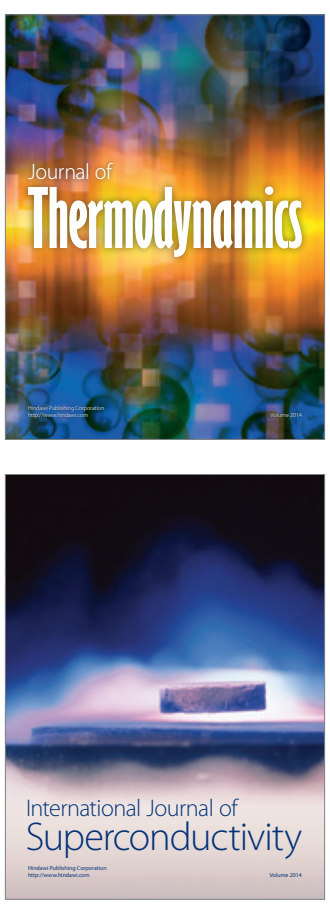
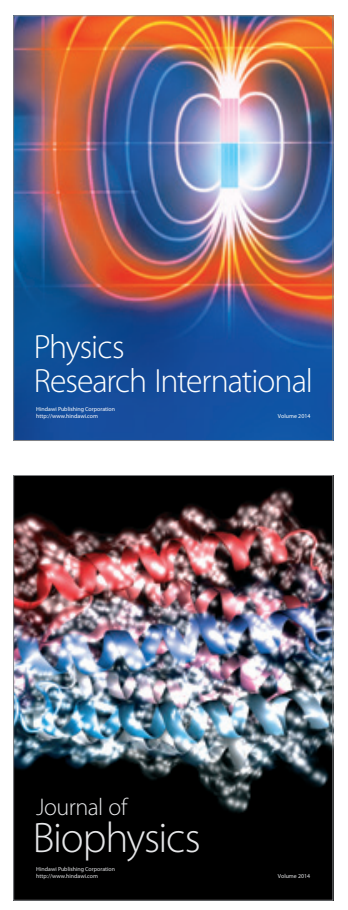
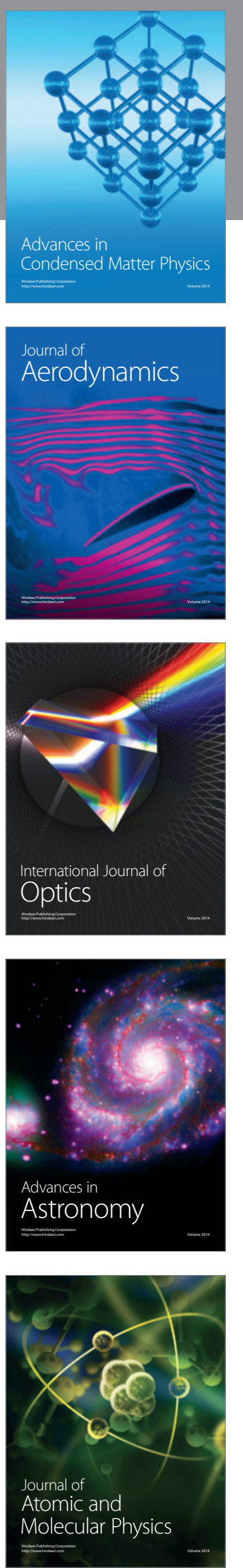